of large institutions at their worst is exported into the community.

Several speakers attempted to inject more realism into the conference proceedings. This was a particularly difficult task for psychiatrists who always risk being labelled Cassandras or reactionaries. It is admittedly the case that the psychiatric consensus on long-term patients has in the past been inaccurate and unduly pessimistic, partly as a result of that distancing from the actualities of their illnesses and their lives which others now seem to be repeating and from which we are not yet free.
The latest King's Fund annual report calls for "a return to some fundamental principles about what it is that community care is intended to achieve, for whom and at what cost". This consensus statement will be useful if it unwittingly serves to underline some of these principles; for all the groups concerned.

David Abrahamson Consultant Psychiatrists (Rehabilitation) Goodmayes Hospital, Goodmayes, Ilford, Essex

\title{
A Proposal to the Griffiths Enquiry into Community Care from the Interdisciplinary Association of Mental Health Workers
}

The Griffiths Review Team has recently been presented with a proposal for a new interagency approach to the planning, financing and management of community care from the Interdisciplinary Association of Mental Health Workers (IAMHW). This submission to Sir Roy Griffiths suggests the establishment of community care consortia.

A consortium is an independent agency with voluntary status, whose membership is drawn from health and social services, housing departments, leisure services, housing associations, voluntary organisations and user groups. The consortium would work in parallel with existing agency structures rather than subsuming them.

Already consortia are beginning to emerge in the field of special needs housing, where the financial advantages have been considerable (although recently this has been threatened by the government's new restrictions on the use of board and lodgings payments). The IAMHW believes that the model could be expanded and adapted to cover other aspects of community care provision.

The familiar blocks to successful joint planning must be removed. The IAMHW identifies these as fragmentation, inability to share resources and lack of incentive for cooperation. The consortium can overcome these problems because:
(1) a larger number of agencies can be involved as equal partners, including users;

(2) agencies can gain access to financial resources more readily because of the consortium's voluntary status, for example housing association finance and private finance can be more readily utilised;

(3) the consortium's role goes beyond planning into finance and management, thus providing continuity and the basis for coherent evaluation.

In offering a model which incorporates the elements of a common budget, a responsible manager and a single agency, the IAMHW proposal is bound to be of interest to the Griffiths enquiry. However, it is distinct from other proposals which incorporate the above elements but which suggest a "lead agency" of either health or social services. The IAMHW model would protect the Local Authority from erosion of its role and involve traditionally marginalised groups of users or voluntary agencies more centrally in planning and management issues.

Many submissions have resisted the notion of a "lead agency" having responsibility for a particular client group, or of significant structural change. The IAMHW shares these reservations, but has a positive alternative proposal in the community care consortium model.

\section{Current Developments in Mental Handicap Services}

A study day on 'Current Developments in Mental Handicap Services' will be held on 9 March 1988 at the Huddersfield Royal Infirmary Lecture Hall. This is a multidisciplinary teaching/training programme which covers various aspects of national and international developments in mental handicap services. Seats are limited. Further details: Dr N. Rao Punukollu, Consultant Psychiatrist, St Luke's Hospital, Crosland Moor, Huddersfield HD4 5RQ (telephone 0484 654711, extension 251). 